\section{Sentinel Lymph Node Biopsy versus Elective Neck Dissection: Long- Term Oncologic Outcomes in Clinically Node-Negative Tongue Cancer}

\author{
Woori Park, Hokyung Jin, Yujin Heo, Han-Sin Jeong, Young-lk \\ Son, Man Ki Chung* and Chung-Hwan Baek*
}

Department of Otorhinolaryngology-Head \& Neck Surgery, Sungkyunkwan University School of Medicine, Samsung Medical Center, Seoul, South Korea

\begin{abstract}
Objectives: To compare the long-term oncologic outcomes of sentinel lymph node biopsy (SLNB) versus elective neck dissection (END) in clinically node-negative ( $\mathrm{CNO}$ ) tongue cancer.

Patients and Methods: This is a retrospective cohort study of patients with cN0 tongue cancer from a single institution, including 91 patients in the SLNB group and 120 patients in the END group.

Results: Overall recurrence rate was no significant difference in the recurrence rate between the two groups. The regional control rate was also comparable between the two groups $(p=0.49)$. The 5 -year RFS was slightly better in the SLNB group $(p=0.427)$. The 5 -year OS was $89.9 \%$ in the SLNB group vs. $91.9 \%$ in the END group ( $p=$ 0.737 ). In propensity-matched subgroup analysis, the type of neck management did not affect RFS or OS.

Conclusions: SLNB showed non-inferior oncologic outcomescompared to END in patients with cNO tongue squamous cell carcinoma.

Keywords: Neck dissection; Node metastasis; Propensity score matching; Oral cancer; Sentinel lymph node biopsy
\end{abstract}

*Corresponding authors: Man Ki Chung, Department of OtorhinolaryngologyHead and Neck Surgery, Samsung Medical Center, Sungkyunkwan University School of Medicine, 81 Irwon-ro, Gangnam-gu, Seoul 06351, South Korea, Tel: + 82 1099335270; E-mail: manki.chung@gmail.com; chungmk@skku.edu

Chung-Hwan Baek, Department of Otorhinolaryngology-Head and Neck Surgery, Samsung Medical Center, Sungkyunkwan University School of Medicine, 81 Irwon-ro, Gangnam-gu, Seoul 06351, South Korea, E-mail: chbaek@skku.edu

Citation: Park W, Jin H, Heo Y, Jeong HS, Son YI, et al. (2020) Sentinel Lymph Node Biopsy versus Elective Neck Dissection: Long-Term Oncologic Outcomes in Clinically Node-Negative Tongue Cancer. J Otolaryng Head Neck Surg 6: 47.

Received: November 07, 2020; Accepted: November 23, 2020; Published: November 30, 2020

Copyright: ( $) 2020$ Park W, et al . This is an open-access article distributed under the terms of the Creative Commons Attribution License, which permits unrestricted use, distribution, and reproduction in any medium, provided the original author and source are credited.

\section{Introduction}

Since the presence of lymph node metastases is one of the most critical factorsin the survivalandrecurrence rate of oral cancer, accurate detection, and proper management of the nodal disease are essential $[1,2]$. It is well known that the occult metastasis rate in clinically node-negative ( $\mathrm{cN} 0$ ) patients with oral cancer ranges from 21 to $35 \%$ and is challenging to detect, even with thorough physical examination and imaging studies $[3,4]$. There has been a long controversy about proper neck management of $\mathrm{cN} 0$ oral cancer patients.Arecent randomized, controlled trial tested the treatment options for $\mathrm{cN} 0$ neck; elective neck dissection (END) vs. therapeutic neck dissection [5]. The patients who had undergone END were reported with improved 3 -year overall survival over therapeutic neck dissection $(80 \%$ vs. $67.5 \%$ ), with an occult metastasis rate of $26.5 \%$. Based on this landmark study, END is accepted as a standard treatment for cN0 oral cancer patients. However, debates remain about the necessity of surgical procedures for over half of patients who do not have any metastatic disease [4].

Recently, sentinel lymph node biopsy (SLNB) is gaining popularity because many studies support that SLNB is a useful staging procedure to detect occult nodal metastasis accurately, theoretically helping three-quarters of patients with $\mathrm{cNO}$ oral squamous cell carcinoma to avoid unnecessary surgery [6-15]. According to other prospective, multicenter trials, the negative predictive value of the SLNB procedure is reported to be around 95\%, depending on the subsite of the tumor $[6,10]$. False-negative or false-omission rates were $9.8 \% \sim 14 \%$, which should be maintained beneath $5 \%$ [16]. Despite recognizing the acceptable diagnostic accuracy of detecting the occult nodal metastasis using the SLNB procedure, there are still hurdles for its widespread application in clinical practice by many head and neck surgeons [17]. One of the hurdles is the scarcity of directly comparingoncological outcomes of SLNB with END to justify routine SLNB application $[18,19]$.

This study aims to evaluate the oncologic safety of SLNB in the management of $\mathrm{cNO}$ oral tongue cancer in direct comparison with END. From a retrospective cohort study of a single institution, we compared the regional control rate, the recurrence-free survival (RFS), and the two groups' overall survival (OS). A propensity score analysis was performed for more balanced comparisons, matching the resection margin to reduce the retrospective design's potential bias.

\section{Patients and Methods}

\section{Patients}

Retrospective cohort enrollments and review of medical records were exempt from the patients' informed consent by the institutional review board of our institution. We enrolled patients who had tongue cancer with cN0 early tongue squamous cell carcinoma treated surgically in Samsung Medical Center between January 1995 and December 2018 in the study. Patients with advanced T stage (T3 or T4) or those who had undergone other tongue cancer treatments before 
surgery were excluded. To distinguish the recurrence and failure of positive node detection, cases with short follow up within six months were also eliminated. Physical evaluation, computed tomography, magnetic resonance imaging, and positron emission tomography were evaluated as a preoperative workup for clinical nodal stagingIf necessary, ultrasonography-guided fine-needle aspiration cytology was also performed.

In our institution, the treatment of choice for the patients with $\mathrm{cN} 0$ tongue cancer has been surgical resection of the primary tumor with END since the establishment of the head and neck cancer center in January 1995. As described in the previous study, SLNB was introduced in our institution after 2002, starting with the validation phase to test the feasibility and the safety of the procedure [20]. After 2007, an SLNB alone trial was applied in eligible patients- designed to do the subsequent neck dissection only in cases with positive sentinel lymph node(s) in the pathologic examination. Since 2007, cN0 tongue cancer patients who consented to the SLNB procedure have undergone SLNB alone trial, while the rest received conventional END for the cN0 neck management.

Adjuvant treatments, including radiation with/without chemotherapy, were performed onpatients with a high-risk feature in the final pathologic report, such as a positive node or advanced $\mathrm{T}$ stage.

\section{Neck management}

We used END to remove the ipsilateral lymph nodes located in neck-level I-III or IV, depending on preoperative imaging studies' findings. The SLNB procedure was performed,as described previously [21]. The radioactive tracer, technetium $99 \mathrm{~m}$ prepared with tin colloid (Amerscan ${ }^{\mathrm{TM}}$ Hepatate II $^{\mathrm{TM}}$; Nycomed Amersham Health, London, U.K.), was injected in the submucosal layer around the circumference of the primary tumor $(5-6 \mathrm{mCi}$ in $0.6 \mathrm{~mL})$. Dynamic lymphoscintigraphy was done in the anterior and lateral views before surgery. During operation, all radioactive lymph nodes were identified with a Navigator GPS hand-held gamma probe (Tyco Health Care, Mansfield, MA, U.S.A.) and were given thorough transcervical dissection for the removal of the primary tumor. If the sentinel lymph node was not detected by lymphoscintigraphy preoperatively nor by gamma probe during surgery, END was to be performed. In our study, none of the cases showed the failure of sentinel node identification. The mean number of sentinel nodes dissected during surgery was 2.84 (range 1-7).

Sentinel lymph nodes were divided into multiple equal levels of approximately $2-\mathrm{mm}$ thickness through their longest axes and separately frozen with an Optimal Cutting Temperature compound. One section for each block was evaluated using frozen section analysis with hematoxylin and eosin (H\&E) staining. After the frozen section diagnosis, the frozen tissue blocks were melted, fixed in $10 \%$ neutral buffered formalin, and embedded in paraffin. These paraffin blocks were serially sectioned at $250 \mu \mathrm{m}$ (step-serial sectioning), and six sections from each level within the block were H\&E stained and examined for possible metastasis. We did further immunohistochemical analysis for cytokeratin (AE1/AE3) to reveal any undetected micrometastasis if the node was free from tumors. If sentinel lymph node(s) showed a metastatic tumor in frozen biopsy or permanent pathology, subsequent therapeutic neck dissection was done. Decisions on the postoperative, adjuvant treatment were made by the multidisciplinary tumor board, assessing all the clinicopathological factors.
Recurrence was defined as a new diagnostic lesion inthe neck detected at least six months after the end of treatment. The lesion developed within six months was regarded as a failure of neck dissection.

\section{Statistical analysis}

The two groups' clinical characteristics were evaluated, including age, sex, clinical and pathologic stage based on the AJCC $7^{\text {th }}$ edition, resection margin, depth of invasion, and presence of perineural invasion / lymphovascular invasion.

Patient characteristics were compared for equality by the Mann-Whitney U-test for continuous variables and $\chi^{2}$ test or Fisher's exact test for categorical data.Propensity score matching analysis allowed the adjustment of baseline patients' characteristics between the END and the SLNB groups (one-to-one matching based on propensity scores). We used a binary logistic regression model to develop a propensity score for each patient. The depth of invasion, a critical factor for recurrence and survival, wasincluded in the propensity score model. Matching was done using calipers of a width of 0.5 of the standard deviation of the propensity score's logit. The standardized difference between unmatched and matched groups was 0.17. A doubly robust method was performed to correct the remained bias.

RFS and OS were analyzed by Kaplan-Meier statistics. We used the log-rank test to compare survival rates between the two groups and multivariate analysis to find the correlation between survival and each clinicopathological variable. Statistical packages of R and SAS version 9.4 (SAS Institute, Cary, NC) were used for statistical analyses, and a $p<0.05$ was considered statistically significant.

\section{Results}

A total of 211 patients were enrolled in the study, with 91 patients in the SLNB group and 120 in the END group. Subject characteristics are described in table 1. Age and sex distribution were similar between the two groups. The SLNB group had more patients diagnosed as cT1 stage than the END group (SLNB vs. END, $80.2 \%$ vs. $54.2 \%$, $p<0.001)$.

In postoperative pathological data, the END group showed worse features than did the SLNB group, with greater depth of invasion (6.96 mm vs. $5.29 \mathrm{~mm}, p=0.009)$ andthe more frequent presence of lymphovascular invasion $(15.8 \%$ vs. $4.4, p=0.013)$. The resection margin of SLNB was greater than END's $(5.66 \mathrm{~mm}$ vs. $4.63 \mathrm{~mm}$, $p=0.001$ ). The mean follow-up was 47.2 months, with 38.2 months in the END group and 58.9 months in the SLNB group.

The total number of $\mathrm{pN}+$ patients after $\mathrm{cN} 0$ neck management was $25(11.8 \%)$. It was significantly higher in END group (15.9\%) than in SLNB group $(6.6 \%)(p=0.040)$ (Figure 1). In $\mathrm{pN}+$ in END group, $89.5 \%$ of patients had adjuvant treatment (postoperative radiotherapy with or without chemotherapy), while $66.7 \%$ of the SLNB group underwent adjuvant treatment.

32 of 211 patients $(15.1 \%)$ were reported with recurrence. The rate of regional recurrence was $10.0 \%(21 / 211) .11$ patients of SLNB group (12.0\%) and 10 patients of ENB group (8.3\%) showed regional recurrence $(p=0.49)$. Duration to recur is similar between the two groups (SLNB vs. END, 592.26 vs. 606.19 days, range 23-4214 days). The failure of neck dissection (rates of regional metastasis within six months) in both groups was similar; $4.4 \%(4 / 91)$ in the SLNB group and $3.3 \%(4 / 120)$ in the END group $(p=0.73)$. 
Citation: Park W, Jin H, Heo Y, Jeong HS, Son YI, et al. (2020) Sentinel Lymph Node Biopsy versus Elective Neck Dissection: Long-Term Oncologic Outcomes in Clinically Node-Negative Tongue Cancer. J Otolaryng Head Neck Surg 6: 47.

\begin{tabular}{|c|c|c|c|c|}
\hline No. $(\%)$ & $\begin{array}{l}\text { Total patients } \\
\quad(N=\mathbf{2 1 1})\end{array}$ & $\begin{array}{c}\text { END } \\
(n=120)\end{array}$ & $\begin{array}{l}\text { SLNB } \\
(n=91)\end{array}$ & $\boldsymbol{P}$ \\
\hline \multicolumn{5}{|l|}{ Demographic data } \\
\hline Male & $129(56.9)$ & $70(58.3)$ & $59(64.8)$ & \multirow{2}{*}{0.414} \\
\hline Female & $82(38.9)$ & $50(41.7)$ & $32(35.2)$ & \\
\hline Age (years) & $53.12 \pm 13.63$ & $54.52 \pm 13.34$ & $51.27 \pm 13.86$ & 0.086 \\
\hline \multicolumn{5}{|l|}{ Preoperative data } \\
\hline cT1/T2 & $138 / 73$ & $65 / 55$ & $73 / 18$ & \multirow{2}{*}{$<0.001$} \\
\hline \multicolumn{4}{|l|}{ Postoperative data } & \\
\hline pT1/T2/T3/T4 & $127 / 74 / 6 / 4$ & $57 / 57 / 5 / 1$ & $70 / 17 / 1 / 3$ & $<0.001$ \\
\hline Resection margin (mm) & $5.07 \pm 2.34$ & $4.63 \pm 2.00$ & $5.66 \pm 2.63$ & 0.001 \\
\hline Depth of invasion (mm) & $6.24 \pm 4.63$ & $6.96 \pm 4.80$ & $5.29 \pm 4,25$ & 0.009 \\
\hline Perineural invasion, $n(\%)$ & $29(13.7)$ & $21(17.5)$ & $8(8.8)$ & 0.106 \\
\hline $\begin{array}{c}\text { Pathologically positive lymph } \\
\text { node, } n(\%)\end{array}$ & $25(11.8)$ & $19(15.9)$ & $6(6.6)$ & 0.040 \\
\hline $\begin{array}{l}\text { Follow up period (month), mean } \\
\text { [range] }\end{array}$ & $47.2[5.8-193.9]$ & $38.2[5.8-193.9]$ & $58.9[7.9-160.0]$ & $<0.001$ \\
\hline
\end{tabular}

Table 1: Subject characteristics.

END elective neck dissection, SNLB sentinel lymph node biopsy

*AJCC $7^{\text {th }}$ edition

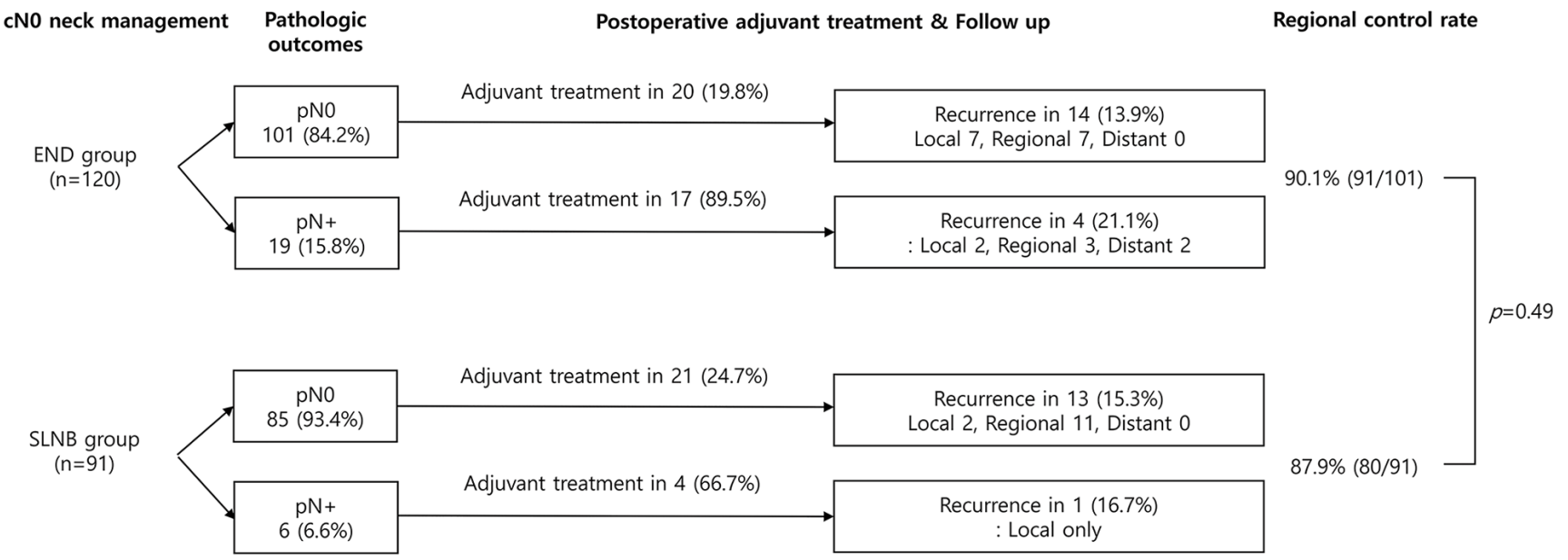

Figure 1: Adjuvant treatment and pattern of recurrence.

Most patients with recurrence (28/32, 87.5\%) had had salvage surgery for recurrence. Only four patients got radiation or chemotherapy for recurrence due to refusal of surgery and distant metastasis. 18 patients alive without disease, three patients alive with disease, and 11 patients died for the disease at the last follow-up. Regional control rate showed no statistical difference (SLNB vs END, 87.9\% vs $90.1 \%, p=0.49)$.

RFS was slightly better in the SLNB group; however, there was no statistical significance $(84.6 \%$ in the SLNB group vs. $79.5 \%$ in the END group, $p=0.427$ ) (Figure 2A). The Kaplan-Meier survival estimate of the two groups was compared as the 5-year OS of patients was $89.9 \%$ in the SLNB group vs. $91.9 \%$ in the END group ( $p=$ 0.737) (Figure 2B).
Cox regression analysis was done to identify the prognostic factors for the RFS and OS. For the RFS, sex and the depth of invasion tended toward significance, but not the type of neck management (Table 2). The deeper invasion was the significant prognostic factor for worse OS (hazard ratios 1.114) (Table 3).

We used propensity score matching to adjust the uneven distribution of critical factors, depth of invasion for the primary oncologic outcomes. As a result, subgroups of 79 patients from each group were generated (Table S1). When the two subgroups were analyzed with the Cox regression method, the neck management type did not influence the prognosis nor recurrence (Table 4). After doubly robust method analysis, the type of neck management effect on the RFS and OS was not evident (Figure 3). 
Citation: Park W, Jin H, Heo Y, Jeong HS, Son YI, et al. (2020) Sentinel Lymph Node Biopsy versus Elective Neck Dissection: Long-Term Oncologic Outcomes in Clinically Node-Negative Tongue Cancer. J Otolaryng Head Neck Surg 6: 47.

\section{A}

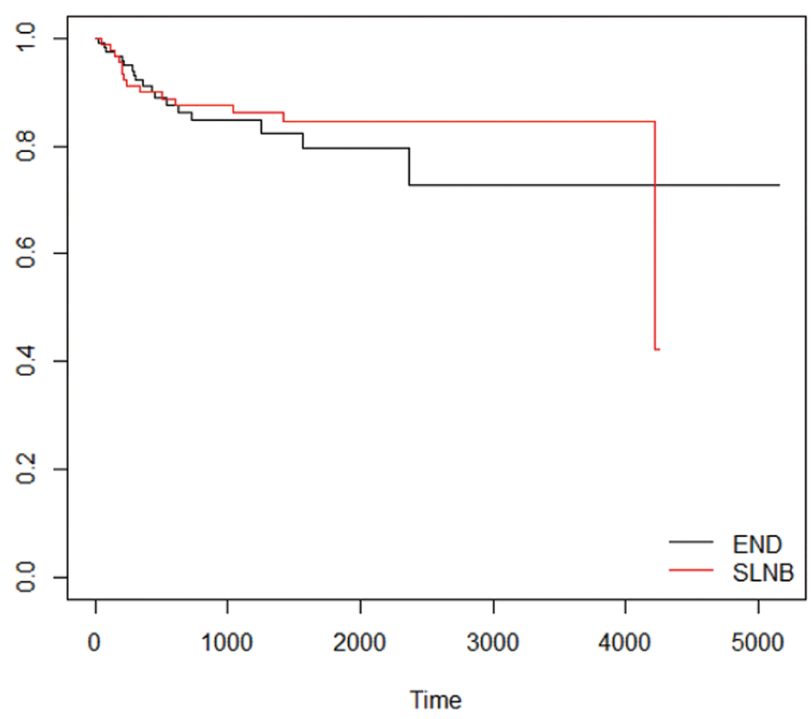

B

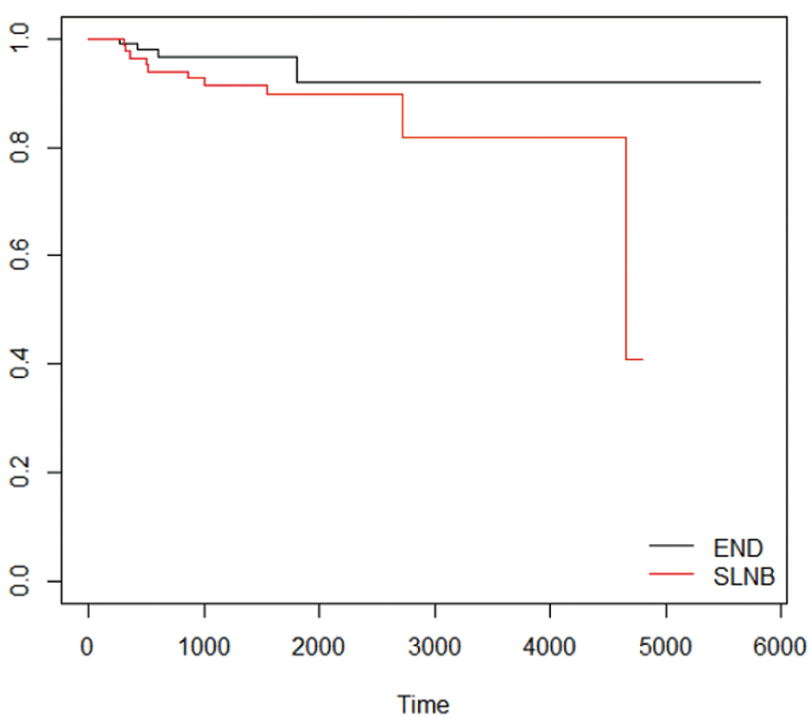

Figure 2: Recurrence rate and overall survival (A) The 5-year recurrence rate. END 79.5\% vs SLNB 84.6\% ( $p=0.427)$ (B) The 5-year overall survival. END $91.9 \%$ vs SLNB $89.9 \%(p=0.737)$.

\begin{tabular}{|c|c|c|c|c|c|c|c|c|}
\hline \multirow[t]{2}{*}{ Variables } & \multirow[b]{2}{*}{ Reference } & & \multicolumn{3}{|c|}{ Univariate analysis } & \multicolumn{3}{|c|}{ Multivariate analysis } \\
\hline & & & HR & $95 \%$ C.I. & $P$ & HR & 95\% C.I. & $P$ \\
\hline Sex & Male & Female & 0.291 & $0.108-0.788$ & 0.015 & 0.332 & $0.136-0.814$ & 0.016 \\
\hline Age & \multicolumn{2}{|c|}{ Continuous } & 0.991 & $0.962-1.021$ & 0.544 & & & \\
\hline T stage* & \multicolumn{2}{|c|}{$\begin{array}{l}\mathrm{T} 1 \\
\mathrm{~T} 2 \\
\mathrm{~T} 3 \\
\mathrm{~T} 4 \\
\end{array}$} & \begin{tabular}{c|c}
1 \\
3.045 \\
3.116 \\
0.000
\end{tabular} & $\begin{array}{c}1.158-8.004 \\
0.285-34.133 \\
0.000-\end{array}$ & $\begin{array}{l}0.024 \\
0.352 \\
0.999\end{array}$ & & & \\
\hline N stage* & No & $\mathrm{N}+$ & 1.126 & $0.329-3.855$ & 0.850 & & & \\
\hline $\begin{array}{l}\text { Resection } \\
\text { margin }\end{array}$ & \multicolumn{2}{|c|}{ Continuous } & 0.972 & $0.807-1.170$ & 0.764 & & & \\
\hline $\begin{array}{l}\text { Depth of inva- } \\
\text { sion }\end{array}$ & \multicolumn{2}{|c|}{ Continuous } & 1.078 & $0.974-1.192$ & 0.146 & 1.070 & $1.002-1.143$ & 0.043 \\
\hline LVI & Absent & Present & 0.000 & $0.000-$ & 0.998 & & & \\
\hline $\begin{array}{l}\text { Type of neck } \\
\text { management }\end{array}$ & END & SLNB & 1.368 & $0.551-3.394$ & 0.499 & 0.914 & $0.448-1.865$ & 0.804 \\
\hline
\end{tabular}

Table 2: Cox regression analysis of risk factors affecting recurrence-free survival.

LVI lymphovascular invasion, PNI perineural invasion, END elective neck dissection, SNLB sentinel lymph node biopsy

*AJCC $7^{\text {th }}$ edition

\section{Discussion}

This study compared the long-term oncologic outcomes between END and SLNB in cN0 tongue cancer patients with a mean follow-up of 47.2 months, using a retrospective cohort from a single institution. We found that the two groups' regional control rates were comparably excellent $(91.7 \%$ vs. $88.9 \%, p=0.49)$ and without statistical difference. Also, the 5-year OS and RFS did not differ between the two groups (SLNB group vs. END group: OS, $89.9 \%$ vs. $91.9 \%$, log-rank $p=0.737$; RFS, $84.6 \%$ vs. $79.5 \%$, log-rank $p=0.427$ ). The analysis of patients from 2007 revealed comparable results with the whole data set (Table S2 and Figure S1). Furthermore, postoperative clinical progress was described and compared in detail between the two groups. This finding could give head and neck surgeons informative data to introduce the SNLB procedure in their clinical practice.

The study's oncologic results are similar to a previous study, which retrospectively compared 30 SLNB patients and 52 END patients with oral tongue squamous cell carcinoma [19]. According to the previous study, the regional recurrence rate was $13.3 \%(4 / 30)$ in the SLNB group and $9.6 \%(5 / 52)$ in the END group, and RFS, as well as OS, were comparable between the two groups without statistical differences (10-year RFS, $72.3 \%$ vs. $73.3 \%$; 10 -year OS, $43.3 \%$ vs. 
Citation: Park W, Jin H, Heo Y, Jeong HS, Son YI, et al. (2020) Sentinel Lymph Node Biopsy versus Elective Neck Dissection: Long-Term Oncologic Outcomes in Clinically Node-Negative Tongue Cancer. J Otolaryng Head Neck Surg 6: 47.

\begin{tabular}{|c|c|c|c|c|c|c|c|c|}
\hline \multirow[t]{2}{*}{ Variables } & \multirow[b]{2}{*}{ Reference } & & \multicolumn{3}{|c|}{ Univariate analysis } & \multicolumn{3}{|c|}{ Multivariate analysis } \\
\hline & & & HR & 95\% C.I. & $P$ & HR & 95\% C.I. & $P$ \\
\hline Sex & Male & Female & 0.262 & $0.048-1.420$ & 0.120 & 0.279 & $0.061-1.267$ & 0.098 \\
\hline Age & \multicolumn{2}{|c|}{ Continuous } & 1.018 & $0.970-1.068$ & 0.474 & 1.046 & $1.002-1.092$ & 0.038 \\
\hline T stage* & \multicolumn{2}{|c|}{$\begin{array}{l}\text { T1 } \\
\text { T2 } \\
\text { T3 } \\
\text { T4 }\end{array}$} & $\begin{array}{c}1 \\
4.493 \\
0.000 \\
68.498\end{array}$ & $\begin{array}{c}0.968-20.858 \\
0.000- \\
2.787-1683.532\end{array}$ & $\begin{array}{l}0.055 \\
0.999 \\
0.010\end{array}$ & & & \\
\hline N stage* & No & $\mathrm{N}+$ & 2.403 & $0.462-12.494$ & 0.297 & & & \\
\hline $\begin{array}{c}\text { Resection } \\
\text { margin }\end{array}$ & \multicolumn{2}{|c|}{ Continuous } & 1.090 & $0.850-1.397$ & 0.498 & & & \\
\hline $\begin{array}{l}\text { Depth of inva- } \\
\text { sion }\end{array}$ & \multicolumn{2}{|c|}{ Continuous } & 1.101 & $0.952-1.274$ & 0.194 & 1.114 & $1.013-1.225$ & 0.026 \\
\hline LVI & Absent & Present & 0.000 & $0.000-$ & 0.998 & & & \\
\hline PNI & Absent & Present & 0.489 & $0.044-5.390$ & 0.559 & & & \\
\hline $\begin{array}{l}\text { Type of neck } \\
\text { management }\end{array}$ & END & SLNB & 5.374 & $1.160-24.893$ & 0.032 & 2.754 & $0.844-8.983$ & 0.093 \\
\hline
\end{tabular}

Table 3: Cox regression analysis of risk factors affecting overall survival.

LVI lymphovascular invasion, PNI perineural invasion, END elective neck dissection, SNLB sentinel lymph node biopsy

*AJCC $7^{\text {th }}$ edition

\begin{tabular}{|c|c|c|c|c|c|c|c|c|}
\hline \multirow{2}{*}{ Variables } & & & \multicolumn{3}{|c|}{ Recurrence-free survival } & \multicolumn{3}{|c|}{ Overall survival } \\
\hline & Reference & & HR & 95\% C.I. & $P$ & HR & 95\% C.I. & $P$ \\
\hline $\begin{array}{c}\text { Resection } \\
\text { margin }\end{array}$ & & & 0.909 & $0.758-1.090$ & 0.305 & 0.943 & $0.736-1.208$ & 0.943 \\
\hline $\begin{array}{l}\text { Depth of inva- } \\
\text { sion }\end{array}$ & & & 1.063 & $0.977-1.158$ & 0.157 & 1.113 & $0.990-1.252$ & 0.074 \\
\hline $\begin{array}{l}\text { Type of neck } \\
\text { management }\end{array}$ & END & SLNB & 0.814 & $0.356-1.860$ & 0.626 & 2.144 & $0.563-8.172$ & 0.264 \\
\hline
\end{tabular}

Table 4: Multivariate analysis of risk factors affecting recurrence and survival after propensity matching.

\section{A}

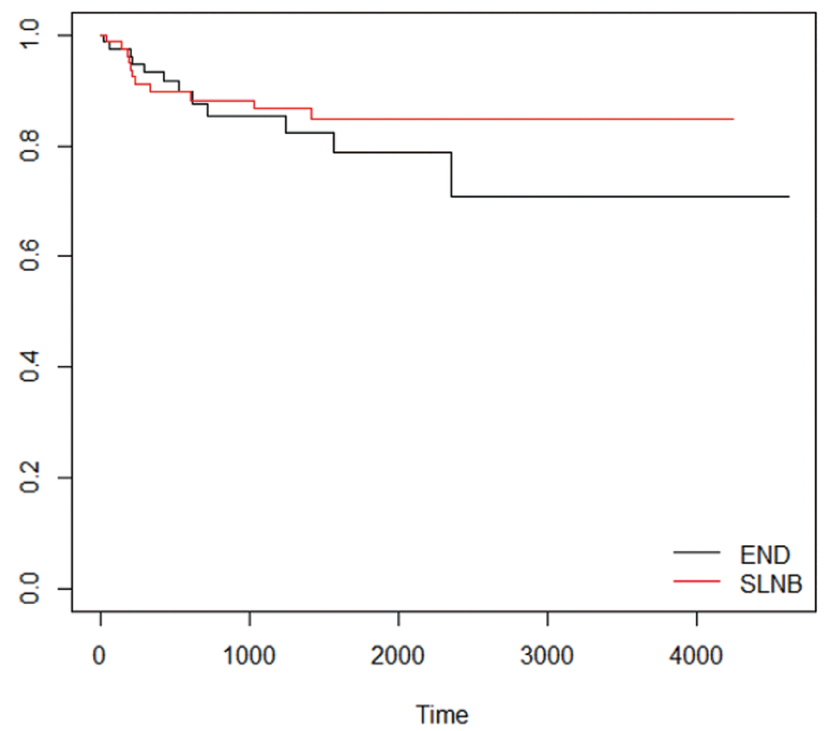

B

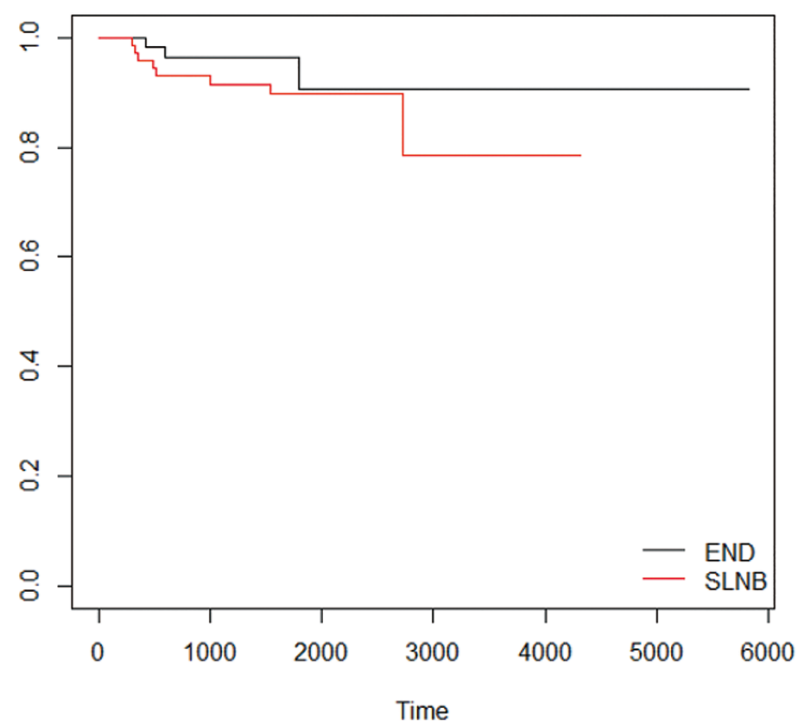

Figure 3: Propensity matching analysis (A) The 5-year recurrence rate. END 78.7\% vs SLNB $84.8 \%$ (p=0.423) (B) The 5-year overall survival. END 90.6\% vs SLNB $89.7 \%(\mathrm{p}=0.899)$. 
Citation: Park W, Jin H, Heo Y, Jeong HS, Son YI, et al. (2020) Sentinel Lymph Node Biopsy versus Elective Neck Dissection: Long-Term Oncologic Outcomes in Clinically Node-Negative Tongue Cancer. J Otolaryng Head Neck Surg 6: 47.

44.2\%). These findings suggest that the SLNB could be a substitute modality for END without any influence on the survival.

Commonly cited advantages of the SLNB are that patients with no sign of metastases on sentinel lymph nodes could avoid neck dissection. Individual treatment could reduce both morbidity and cost [7]. Moreover, based on the postoperative course's detailed analysis, the number of patients who had adjuvant treatments (SLNB 27.5\% vs. END $30.8 \%, p=0.65$ ) was similar in the two groups without any adverse effect on prognosis (Figure 1). Both groups' recurrence rates showed similar outcomes, even though pN0 patients in the SLNB group did not receive additional therapeutic neck dissection nor adjuvant treatment. About a third of $\mathrm{pN}+$ patients in the SLNB group did not receive postoperative adjuvant treatments, and they did not experience any recurrence during follow up.

To maintain an acceptable oncologic outcome in SLNB alone trial, the false-negative rate must be as low as $5 \%$ (pN0 sentinel lymphnode progressing within two years)[16]. There wereeight regional recurrent cases $(3.3 \%$ and $4.4 \%)$ within six months in each group, considereda failure of neck management or false-negative. Salvage operations were done in all eight patients, and as result, five patients survived without any evidence of disease, one patient still alive with the disease, and two patients died from the disease. This finding is comparable with a previous study that reported long-term follow-up outcomes and a nodal failure pattern of SLNB in oral squamous cell carcinoma [22]. Among 11 patients with regional recurrence in SLNB group, it was found that three cases of contralateral nodal recurrences and one ipsilateral nodal recurrence at almost ten years after the SLNB. As highlighted in our previous report about the SLNB alone trial, a stringent follow-up protocol with salvage treatment is critical to maintaining acceptable oncologic outcomes [20]. Close follow-up is mandatory for positive SLNB patients, who are at higher risk of nodal recurrence and worse prognosis than do negative SLNB patients.

In a recent study, a large number of patients with stage I-II oral squamous cell carcinoma ( 240 patients of the SLNB group and 8088 patients of the END group) were retrieved and analyzed from the National Cancer Data Base (NCDB) of the United States [18].The study's outcomes were similar to the present study in that 3-year OS was equivalent between the two groups ( $82.0 \%$ after SLNB vs. $77.5 \%$ after END, $p=0.40$ ). Interestingly, SLNB showed a significantly decreased length of postoperative hospital stay over END and an absolute difference in a 30 -day mortality rate $(0 \%$ in SLNB vs. $0.7 \%$ END). Despite all these advantages, it is found that the SLNB procedure are rarely used for stage I-II oral cancer, warranting a multicenter randomized control trial comparing the SLNB vs. the END to produce level-I evidence for SLNB in early oral cancer [18].

This study contains the common drawbacks of all studies using a retrospective cohort, including the selection bias. Firstly, in the subject characteristics, key pathologic features, such as surgical resection margin and the depth of invasion, were not equally distributed between the SLNB group and the END group. To overcome the inequality of adverse pathologic factors, we used propensity score matching analysis based on the resection margin to generate 79 subgroup patients from each group. Secondly, we did not investigate the other controversial issues related to each procedure, for example, cost-effectiveness, surgery-related complications, or quality-of-life comparisons.

\section{Conclusions}

According to this retrospective cohort analysis, the SLNB did not have worse oncologic outcomes than the END in patients with $\mathrm{cN} 0$ tongue squamous cell carcinoma. Considering that many patients could avoid unnecessary, invasive treatment after nodal staging by the SLNB, this procedure is highly recommended in clinical practice. A watchful follow-up protocol, as well as a potential plan for salvage management, should be warranted to obtain excellent outcomes in a long-term period.

\section{Contributions of Authors}

Young-Ik Son, Han-Sin Jeong, Man Ki Chung, and Chung-Hwan Baek collected the data and designed the study.

Woori Park, Hokyung Jin, Yujin Heo,Man Ki Chung, and ChungHwan Baek interpreted the experimental data, prepared all figures, and wrote the main manuscript text.

All authors reviewed and confirmed the manuscript.

\section{Conflict of Interest}

None.

\begin{tabular}{|c|c|c|c|}
\hline No. $(\%)$ & $\begin{array}{c}\text { END } \\
(n=79)\end{array}$ & $\begin{array}{c}\text { SLNB } \\
(n=79)\end{array}$ & $P$ \\
\hline \multicolumn{4}{|l|}{ Demographic data } \\
\hline Male & $53(67.1)$ & $50(63.3)$ & \multirow[t]{2}{*}{0.738} \\
\hline Female & $26(32.9)$ & $29(36.7)$ & \\
\hline Age (years, SD) & $53.46(12.26)$ & $52.18(14.07)$ & 0.543 \\
\hline \multicolumn{4}{|l|}{ Preoperative data } \\
\hline cT1/T2 & $56 / 23$ & $61 / 18$ & \multirow[t]{2}{*}{0.468} \\
\hline \multicolumn{3}{|l|}{ Postoperative data } & \\
\hline Resection margin (mm, SD) & $4.84(2.10)$ & $5.49(2.61)$ & 0.275 \\
\hline Depth of invasion (mm, SD) & $5.95(4.11)$ & $5.25(4.07)$ & 0.171 \\
\hline Lymphovascular invasion, $n$ (\%) & $7(8.9)$ & $4(5.1)$ & 0.150 \\
\hline Pathologically positive lymph node, $n$ (\%) & $4(5.1)$ & $5(6.3)$ & 0.055 \\
\hline
\end{tabular}

Table S1: Subject characteristics (matching). 
Citation: Park W, Jin H, Heo Y, Jeong HS, Son YI, et al. (2020) Sentinel Lymph Node Biopsy versus Elective Neck Dissection: Long-Term Oncologic Outcomes in Clinically Node-Negative Tongue Cancer. J Otolaryng Head Neck Surg 6: 47.

\begin{tabular}{|c|c|c|c|c|}
\hline No. $(\%)$ & $\begin{array}{l}\text { Total patients } \\
\quad(N=186)\end{array}$ & $\begin{array}{c}\text { END } \\
(n=102)\end{array}$ & $\begin{array}{l}\text { SLNB } \\
(n=84)\end{array}$ & $P$ \\
\hline \multicolumn{5}{|l|}{ Demographic data } \\
\hline \multicolumn{5}{|l|}{ Sex, $n(\%)$} \\
\hline Male & $110(59.1)$ & $57(55.9)$ & $53(63.1)$ & \multirow[t]{2}{*}{0.369} \\
\hline Female & $76(40.9)$ & $45(44.1)$ & $31(36.9)$ & \\
\hline Age (years) & $53.00 \pm 13.98$ & $54.27 \pm 14.06$ & $51.45 \pm 13.82$ & 0.171 \\
\hline \multicolumn{5}{|l|}{ Preoperative data } \\
\hline $\mathbf{c T 1} / \mathbf{T} 2$ & $126 / 60$ & $57 / 45$ & $69 / 15$ & \multirow[t]{2}{*}{$<0.001$} \\
\hline \multicolumn{4}{|l|}{ Postoperative data } & \\
\hline pT1/T2/T3/T4 & $115 / 62 / 6 / 3$ & $49 / 47 / 5 / 1$ & $66 / 15 / 1 / 2$ & $<0.001$ \\
\hline Resection margin (mm) & $5.12 \pm 2.40$ & $4.57 \pm 1.97$ & $5.79 \pm 2.69$ & 0.001 \\
\hline Depth of invasion (mm) & $5.97 \pm 4.57$ & $6.59 \pm 4.62$ & $5.17 \pm 4.42$ & 0.037 \\
\hline Lymphovascular invasion, $n(\%)$ & $23(12.4)$ & $19(18.6)$ & $4(4.8)$ & 0.006 \\
\hline Perineural invasion, $n$ (\%) & 29(15.6) & $21(20.6)$ & $8(9.5)$ & 0.044 \\
\hline $\begin{array}{c}\text { Pathologically positive lymph } \\
\text { node, } n(\%)\end{array}$ & $20(10.8)$ & $14(13.7)$ & $6(7.1)$ & 0.163 \\
\hline $\begin{array}{c}\text { Follow up period (month), mean } \\
\text { [range] }\end{array}$ & $40.39[6.2-141.6]$ & $39.0[6.2-119.7]$ & $52.9[7.9-141.6]$ & $<0.001$ \\
\hline
\end{tabular}

Table S2: Subject characteristics (data from 2007).

(A)

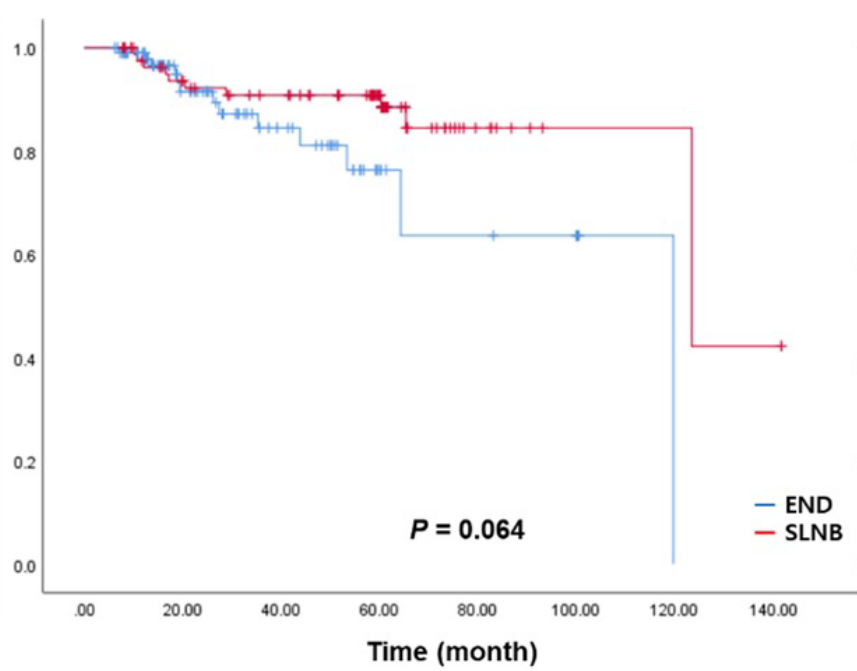

(B) Kaplan-Meier curve - Overall survival

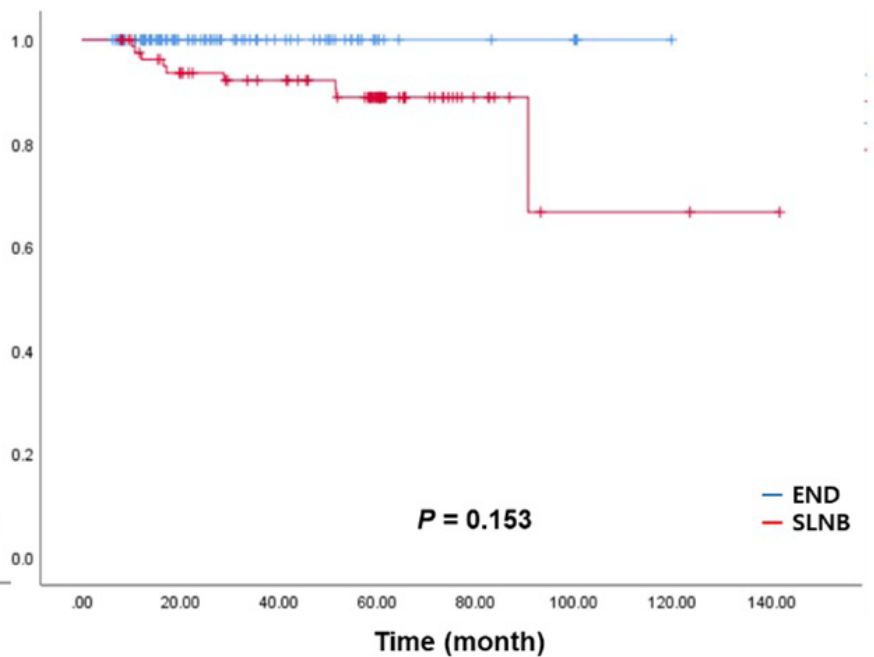

Figure S1: (A) Recurrence rate $(\mathrm{p}=0.064)$ and $(\mathrm{B})$ overall survival $(\mathrm{p}=0.153)$ (data from 2007).

\section{References}

1. Rogers SN, Brown JS, Woolgar JA, Lowe D, Magennis P, et al. (2009) Survival following primary surgery for oral cancer. Oral Oncol 45: 201211.

2. Woolgar JA, Rogers S, West CR, Errington RD, Brown JS, et al.( 1999) Survival and patterns of recurrence in 200 oral cancer patients treated by radical surgery and neck dissection. Oral Oncol 35: 257-265.

3. Teichgraeber JF, Clairmont AA (1984) The incidence of occult metastases for cancer of the oral tongue and floor of the mouth: treatment rationale. Head Neck Surg 7: 15-21.

4. Kligerman J, Lima RA, Soares JR, Prado L, Dias FL, et al. (1994) Supraomohyoid neck dissection in the treatment of T1/T2 squamous cell carcinoma of oral cavity. Am J Surg 168: 391-394.
5. D’Cruz AK, Vaish R, Kapre N, Dandekar M, Gupta S, et al. (2015) Elective versus Therapeutic Neck Dissection in Node-Negative Oral Cancer. N Engl J Med 373: 521-529.

6. Schilling C, Stoeckli SJ, Haerle SK, Broglie MA, Huber GF, et al. (2015) Sentinel European Node Trial (SENT): 3-year results of sentinel node biopsy in oral cancer. Eur J Cancer 51: 2777-2784.

7. Schilling C, Shaw R, Schache A, McMahon J, Chegini S, et al. (2017) Sentinel lymph node biopsy for oral squamous cell carcinoma. Where are we now? Br J Oral Maxillofac Surg 55: 757-762.

8. Samant S (2014) Sentinel node biopsy as an alternative to elective neck dissection for staging of early oral carcinoma. Head Neck 36: 241-246.

9. Flach GB, Bloemena E, Klop WM, van Es RJ, Schepman KP, et al. (2014) Sentinel lymph node biopsy in clinically N0 T1-T2 staged oral cancer: the Dutch multicenter trial. Oral Oncol 50: 1020-1024. 
Citation: Park W, Jin H, Heo Y, Jeong HS, Son YI, et al. (2020) Sentinel Lymph Node Biopsy versus Elective Neck Dissection: Long-Term Oncologic Outcomes in Clinically Node-Negative Tongue Cancer. J Otolaryng Head Neck Surg 6: 47.

10. Civantos FJ, Zitsch RP, Schuller DE, Agrawal A, Smith RB, et al. (2010) Sentinel lymph node biopsy accurately stages the regional lymph nodes for T1-T2 oral squamous cell carcinomas: results of a prospective multi-institutional trial. J Clin Oncol 28: 1395-1400.

11. Wu JX, Hanson M, Shaha AR (2019) Sentinel node biopsy for cancer of the oral cavity. J Surg Oncol 120: 99-100.

12. Krishnamurthy A (2017) Current status and future perspectives of sentinel lymph node biopsy in oral cancers. Indian J Dent Res 8: 239-240.

13. Hernando J, Villarreal P, Alvarez-Marcos F, Gallego L, Garcia-Consuegra L, et al. (2014) Comparison of related complications: sentinel node biopsy versus elective neck dissection. Int J Oral Maxillofac Surg 43: 1307-1312.

14. Den Toom IJ, Heuveling DA, Flach GB, van Weert S, Karagozoglu KH, et al. (2015) Sentinel node biopsy for early-stage oral cavity cancer: the VU University Medical Center experience. Head Neck 37: 573-578.

15. Stoeckli SJ, Alkureishi LW, Ross GL (2009) Sentinel node biopsy for early oral and oropharyngeal squamous cell carcinoma. Eur Arch Otorhinolaryngol 266: 787-793.

16. Garrel R, Poissonnet G, Temam S, Dolivet G, Fakhry N, et al. (2017) Review of sentinel node procedure in $\mathrm{cN} 0$ head and neck squamous cell carcinomas. Guidelines from the French evaluation cooperative subgroup of GETTEC. Eur Ann Otorhinolaryngol Head Neck Dis 134: 89-93.
17. Seim NB, Wright CL, Agrawal A (2016) Contemporary use of sentinel lymph node biopsy in the head and neck. World J Otorhinolaryngol Head Neck Surg 2: 117-125

18. Cramer JD, Sridharan S, Ferris RL, Duvvuri U, Samant S (2019) Sentinel Lymph Node Biopsy Versus Elective Neck Dissection for Stage I to II Oral Cavity Cancer. Laryngoscope 129: 162-169.

19. Fan SF, Zeng ZY, Peng HW, Guo ZM, Wang SL, et al. (2014) Sentinel lymph node biopsy versus elective neck dissection in patients with cT12N0 oral tongue squamous cell carcinoma. Oral Surg Oral Med Oral Pathol Oral Radiol 117: 186-190.

20. Chung MK, Lee GJ, Choi N, Cho JK, Jeong HS, et al. (2015) Comparative study of sentinel lymph node biopsy in clinically N0 oral tongue squamous cell carcinoma: Long-term oncologic outcomes between validation and application phases. Oral Oncol 51: 914-920.

21. Jeong HS, Baek CH, Son YI, Cho DY, Chung MK, et al. (2006) Sentinel lymph node radiolocalization with $99 \mathrm{mTc}$ filtered tin colloid in clinically node-negative squamous cell carcinomas of the oral cavity. J Korean Med Sci 21: 865-870.

22. Moya-Plana A, Auperin A, Guerlain J, Gorphe P, Casiraghi O, et al. (2018) Sentinel node biopsy in early oral squamous cell carcinomas: Long-term follow-up and nodal failure analysis. Oral Oncol 82: 187-194. 


\section{H}

Advances In Industrial Biotechnology | ISSN: 2639-5665

Advances In Microbiology Research | ISSN: 2689-694X

Archives Of Surgery And Surgical Education | ISSN: 2689-3126

Archives Of Urology

Archives Of Zoological Studies | ISSN: 2640-7779

Current Trends Medical And Biological Engineering

International Journal Of Case Reports And Therapeutic Studies | ISSN: 2689-310X

Journal Of Addiction \& Addictive Disorders | ISSN: 2578-7276

Journal Of Agronomy \& Agricultural Science | ISSN: 2689-8292

Journal Of AIDS Clinical Research \& STDs | ISSN: 2572-7370

Journal Of Alcoholism Drug Abuse \& Substance Dependence | ISSN: 2572-9594

Journal Of Allergy Disorders \& Therapy | ISSN: 2470-749X

Journal Of Alternative Complementary \& Integrative Medicine | ISSN: 2470-7562

Journal Of Alzheimers \& Neurodegenerative Diseases | ISSN: 2572-9608

Journal Of Anesthesia \& Clinical Care | ISSN: 2378-8879

Journal Of Angiology \& Vascular Surgery | ISSN: 2572-7397

Journal Of Animal Research \& Veterinary Science | ISSN: 2639-375

Journal Of Aquaculture \& Fisheries | ISSN: 2576-5523

Journal Of Atmospheric \& Earth Sciences | ISSN: 2689-8780

Journal Of Biotech Research \& Biochemistry

Journal Of Brain \& Neuroscience Research

Journal Of Cancer Biology \& Treatment | ISSN: 2470-7546

Journal Of Cardiology Study \& Research | ISSN: 2640-768X

Journal Of Cell Biology \& Cell Metabolism | ISSN: 2381-1943

Journal Of Clinical Dermatology \& Therapy | ISSN: 2378-8771

Journal Of Clinical Immunology \& Immunotherapy | ISSN: 2378-8844

Journal Of Clinical Studies \& Medical Case Reports | ISSN: 2378-880

Journal Of Community Medicine \& Public Health Care | ISSN: 2381-1978

Journal Of Cytology \& Tissue Biology | ISSN: 2378-9107

Journal Of Dairy Research \& Technology | ISSN: 2688-9315

Journal Of Dentistry Oral Health \& Cosmesis | ISSN: 2473-6783

Journal Of Diabetes \& Metabolic Disorders | ISSN: 2381-201X

Journal Of Emergency Medicine Trauma \& Surgical Care | ISSN: 2378-8798

Journal Of Environmental Science Current Research | ISSN: 2643-5020

Journal Of Food Science \& Nutrition | ISSN: 2470-1076

Journal Of Forensic Legal \& Investigative Sciences | ISSN: 2473-733X

Journal Of Gastroenterology \& Hepatology Research | ISSN: 2574-2566
Journal Of Genetics \& Genomic Sciences | ISSN: 2574-2485

Journal Of Gerontology \& Geriatric Medicine | ISSN: 2381-8662

Journal Of Hematology Blood Transfusion \& Disorders | ISSN: 2572-2999

Journal Of Hospice \& Palliative Medical Care

Journal Of Human Endocrinology | ISSN: 2572-9640

Journal Of Infectious \& Non Infectious Diseases | ISSN: 2381-8654

Journal Of Internal Medicine \& Primary Healthcare | ISSN: 2574-2493

Journal Of Light \& Laser Current Trends

Journal Of Medicine Study \& Research | ISSN: 2639-5657

Journal Of Modern Chemical Sciences

Journal Of Nanotechnology Nanomedicine \& Nanobiotechnology | ISSN: 2381-2044

Journal Of Neonatology \& Clinical Pediatrics | ISSN: 2378-878X

Journal Of Nephrology \& Renal Therapy | ISSN: 2473-7313

Journal Of Non Invasive Vascular Investigation | ISSN: 2572-7400

Journal Of Nuclear Medicine Radiology \& Radiation Therapy | ISSN: 2572-7419

Journal Of Obesity \& Weight Loss | ISSN: 2473-7372

Journal Of Ophthalmology \& Clinical Research | ISSN: 2378-8887

Journal Of Orthopedic Research \& Physiotherapy | ISSN: 2381-2052

Journal Of Otolaryngology Head \& Neck Surgery | ISSN: 2573-010X

Journal Of Pathology Clinical \& Medical Research

Journal Of Pharmacology Pharmaceutics \& Pharmacovigilance | ISSN: 2639-5649

Journal Of Physical Medicine Rehabilitation \& Disabilities | ISSN: 2381-8670

Journal Of Plant Science Current Research | ISSN: 2639-3743

Journal Of Practical \& Professional Nursing | ISSN: 2639-568

Journal Of Protein Research \& Bioinformatics

Journal Of Psychiatry Depression \& Anxiety | ISSN: 2573-0150

Journal Of Pulmonary Medicine \& Respiratory Research | ISSN: 2573-0177

Journal Of Reproductive Medicine Gynaecology \& Obstetrics | ISSN: 2574-2574

Journal Of Stem Cells Research Development \& Therapy | ISSN: 2381-2060

Journal Of Surgery Current Trends \& Innovations | ISSN: 2578-7284

Journal Of Toxicology Current Research | ISSN: 2639-3735

Journal Of Translational Science And Research

Journal Of Vaccines Research \& Vaccination | ISSN: 2573-0193

Journal Of Virology \& Antivirals

Sports Medicine And Injury Care Journal | ISSN: 2689-8829

Trends In Anatomy \& Physiology | ISSN: 2640-7752

Submit Your Manuscript: https://www.heraldopenaccess.us/submit-manuscript 